\title{
Communication Code as Pillar of Successful Communication in Social Cultural Institution (by Example of Theatrical Discourse)
}

\author{
Larissa Vikulova, Evgeniia Serebrennikova, Olga Vostrikova, and Liudmila Borbotko
}

Romance Philology department, Institute of Foreign Languages, Moscow City University, 5b Maly Kazenny per., 105064 Moscow Russia

Romance and Germanic Philology department, Institute of Philology, Media Communications and Foreign Languages, Irkutsk State University

English Philology department, Institute of Foreign Languages, Moscow City University, 5b Maly Kazenny per., 105064 Moscow Russia

Language and Translation Studies department, Institute of Foreign Languages, Moscow City University, 5b Maly Kazenny per., 105064 Moscow Russia

\begin{abstract}
The paper attempts to define constituting features of theatrical discourse which determine functioning of the latter in theatre communicative space. Communication code moderates the addresseraddressee interrelations thus playing a key role in the realization of theatrical discourse as a ritualized, institutional and conventional semiotic unit. The study also aims at introducing a typology of theatrical discourse participants and at defining the addressing vector direction. Communication code is estimated as a moderator of theatrical communication processes and an indicator of communication success / failure. The audience is viewed as a social addressee - an element obligatory for theatrical discourse to be externalized. The audience's behavioral pattern is largely attributed to the existing communication code: the audience is conscious of their silent role, the verbal communication being somewhat one-way. Conversely, theatrical discourse implies reaction on behalf of the audience. The communication code significantly affects the temporal and spatial framework of theatre communication alongside the actual theatre space existence. The social cultural institution of theatre is targeted at sustaining the society moral values and forming new cognitive and ethical ones. These functions of theatre are also of primary importance. The research results in the drafted principles of the code of verbal communication applied to theatrical discourse, viz. the principle of temporal and spatial organization; the principle of muteness; the principle of prescript observation and the axiological awareness principle.
\end{abstract}

\section{Introduction}

The study attempts to analyze the mechanisms of communication operating within the framework of theatrical discourse. Internal to the social cultural institution, from its very inception theatrical communication space has been an artistic reflection and embodiment of real life on the stage. Theatrical performance is of quasi-real nature: staged in front of the audience, it is still identical to real life as for its implementation. Belonging to the scenic reality, theatre, however, is not apt to distract the audience from real life. On the contrary, it depicts reality by artistic means. Theatre proves to be one of the most socially demanded art forms due to its immediate response to current social events.

The ultimate goal of the research is to examine theatrical communication code as a mechanism maintaining and sustaining theatrical communication on the stage in front of the audience. Prescripts are one of the peculiarities theatrical communication features in. Accurately observed strict regulations sustain theatrical communication code.

To hit the targeto it is relevant to define the nature of theatrical communication, to list the specific features of the communicators, to specify and classify the facts proving the existence of theatrical communication code. To define the current paradigm and the possibilities to follow, it is of no less importance to trace the changes theatrical communication code has been exposed to diachronically.

\section{Methodology}

The subject matter and goals of the research proved to be paramount while selecting the methods of addressing the material in practice. Theatrical discourse is approached from the pragmalinguistic perspective thus enabling the authors to consider its constituents within the social, communicative and cultural frames. Theatrical discourse is a language phenomenon, subject

\footnotetext{
Corresponding author: 1udmilaborbotko@gmail.com
} 
to examination from anthropocentric positions. Consequently, it can be treated as a a social activity externalized by a theatre company under the director's guidance in front of the audience. The specificity of this discourse-type lies in its unique limited communicative space created between the playwright and the audience. Such communication is possible due to the director's work and actors' performance on the stage. The key target in theatrical communication is to exercise the ultimate esthetic influence on the audience [2]. The authors feel that without defining the medium of implement, the message of communication cannot be conveyed by the playwright in coordination with the director and the company, nor can it be fully grasped by the audience. As B. Gasparov puts it, the author's awareness of actual and prospective addressees, their views, beliefs, interests and intentions are crucial for the moulded theatrical communication space [3].

\section{Results and Discussion}

Theatrical discourse is characterized in accordance with a range of categories revealing its constitutive features. Among them, the foremost positions belong to those of institutionality, conventionality, rituality and regulation [4]. Institutionality implies that theatrical discourse is accomplished within the framework of theatre as a social cultural institution.

The social cultural institution of theatre targets at imbuing moral values and rests upon professional arts, where dramatists and performers account for a board of professionals advocating for theatrical communication code. The suchlike code not only dominates interrelations within the theatre ensemble and determines inter-company relations but also regulates the behavioral patterns of the audience.

Yet, apart from being institutionalized, theatre is both standardized and ritualized. Although following the well-established patterns, theatre proves to be among the most ritualized art forms, despite being largely determined by social and cultural particularities of a certain epoch and sensitively responsive to every change in the society [3]. Theatre is fundamentally standardized. Canons regulating data stream within theatrical discourse are assembled in the form of the communication code. The communication arrangement in question regulates both verbal and non-verbal behavior of theatrical discourse participants; thus theatrical communication displays a combination of linguistic, paralinguistic (dealing with "the smallest fragments of speech") and non-verbal features or "body language" known as kinesics [5].

Participants in theatrical communication (such as playwrights, directors, company, composers, stage workers, etc.) make not only a professional community, but also a discursive community and, in Swales' terms, a collective addresser in charge of staging a play in front of the audience, a collective addressee. The quasi-real nature of theatrical communication claims the audience to obtain the role of a silent observer (the term of $\mathrm{V}$. Babayan). According to his classification of triad dialogues, theatrical communication also represents a triad: "that addresser (actor one) directs his remark or entire speech immediately to the addressee (actor two) along with the probable silent observer. However, addressing the silent observer is indirect" [6]. Observation is the essence of theatre which "took the paralingual form of man, transcended it in a character of a play and passed it back to the ordinary man giving him the role of an observer" [7].

At the same time, theatre implies speaking practices to be targeted at the social addressee accumulating persons in the audience. The social addressee represents a potential observer, perceiving and notifying the state of surrounding environment manifested in each addresser located in different spatial points [8]. Consequently, the process of addressing the theatrical performance is never limited to the audience present in the hall. Recorded or broadcast via the internet, a performance becomes property of the global audience represented by each individual social addressee around the world. Therewith, there emerges the so-called indirect social addressee represented by part of the audience who have not actually seen the performance, but have got familiar with the critical reviews and whose perceptions are derived from personal experience, background, values, etc. Both direct (real viewers) and indirect (round-about obtainers of information) social addressees create a counter-discourse, the respondent discourse forming a specific space that surrounds the initial discourse [8].

\section{Theatrical Communication Space}

A communication event is realized in the theatre physical space. This space is not simply a storing container but a place where 'the speaker's location makes the topos, where the discursive space overlaps the physical space" [7]. In other words, the spectator attending the theatrical performance makes a constitutive of the space both discursive and communicative in its nature.

Theatrical space is cumulative and divided into two parts: the space of the audience hall and that of the stage. Still, the stage was not always meant for play adaptation in the conventional sense. In the XVII-XIX centuries, staging claimed a specific territory like spring platforms for scenes to be dramatized. Church dramas of the Dalmatian-Dubrovnik Renaissance (XVI-XVII centuries), for instance, were performed inside churches as well as on the church porch, in fields and squares [9].

Nevertheless, the stage located in front of the audience hall pretends to be a customary place for theatrical play adaptation. The scenery and technical support of the performance are of primary importance for the physical space of the stage as a showground. The stage action accompanied by specific smells, smoke, noises and scenery, target at convincing the audience of proceedings authenticity.

The customary image of stage has changed over time. Notably, the arrangement of classical English theatre required a vast range of technical and spatial 
resources (most of them unavailable for the modern theatre) to put up Shakespearean works [10]. The performance of that period was accomplished on the following five planes (areas):

1) the proscenium; its advancing towards the audience let them perceive the images' plastique;

2) the backstage; quick change of scenery and props required a certain borderline- a drape separating the backstage it from the proscenium;

3) the upper stage;

4) the small turret above the upper stage;

5) the hatches under the stage.

The suchlike stage construction was undoubtedly more beneficial for scene alternation and congruency than the "box-like" arrangement, usual for that time [11]. A huge amount of stage machinery, typical of Shakespearean theatre, enabled demonstration of various tricks as well the change of scenery without the curtain dropping down. Thus the necessity of intervals was removed.

Nowadays a performance is staged by the theatrical company in front of the audience seated in the semi-dark throughout the performance hall. The blackout in the audience hall serves pragmatic purposes as it is a phatic sign of the performance starting. It was the English tragedian Henry Irving (1838-1905) who at the beginning of the XIX century suggested shading the audience hall on technical grounds: the brightly lit hall, lower footlights along with side lighting from the wings hindered the proper estimation of dramatic lightning. In their turn, the footlights make a borderline between the stage and the audience hall, and the curtain serves as an "article of stage clothing" separating two spaces: those of the stage and of the hall till the performance starts. As M. Yampolskiy puts it, the curtain signifies the audience distancing from events taking place on the stage. Distancing contributes to satisfying the spectators' curiosity about the performance proceedings. The halfdrawn curtain signifies a mystery of which the present spectators become insiders. The magic is over when the performance draws to a close and the curtain drops again [12].

Still we cannot but mention the trend towards experiments in modern theatre which may bring changes to the usual structure of traditional theatre space comprising stage and audience hall. The changes are imbued in the nature of "what Hans-Thies Lehmann calls postdramatic theatre: they do not rely on a dramatic text as a structuring device" [13]. Thus, theatrical action is shifted from the stage to the hall or there appear several platforms for different scenes to be demonstrated simultaneously. In some cases, action recedes the walls of the theatre transferring to squares thus rolling back to the show-booth origins of theatre.

The notions of physical space of the theatre and that of theatrical space formed largely due to and as a consequence of "the movements of both actors and spectators, their perceptions" [6] are to be strictly differentiated. Therefore, theatrical space is formed as a result of performers' actions within the physical space of the theatre. Hence, it is the fundamentally unstable and changeable performance that generates the same changeable theatrical space.

The physical or geometrical space of the theatre is a kind of "container" since the performance participants (the cast and viewers) are inside it. The container is 'hermetically' sealed meaning you cannot get. In case one violates the prescript, one unseals the frame of the space as the light from the door dissects the dark hall. Such a prescript can be viewed in any theatre ticket saying the audience is forbidden to enter the hall after the third bell goes.

Any theatrical space whatever its size, layout or design be, is treated as performative. This implies a possibility of contact maintenance by the participants (viz. among actors and spectators), of moving around and of perceiving what is going on by the addressees. In other words, the physical space of the theatre is performative on the constant basis. It "moulds the space of the particular performance and designates conditions of its comprehension" [2]. As a consequence, the way of organizing the theatrical performative space affects the audience's perception and their feedback. The space becomes a limiting factor. Therefore, it proves reasonable to assume that regulation of theatrical discourse is largely due to the organizational function of theatrical space.

Everything that has been already said above displays a strong link between a prominent theatrical-discourse feature of communication code and the performance location. The location dominates the communication code in theatrical discourse and vice versa. One of illustrative examples of this dates back to the XVII France and Germany/ The theatre there enabled the aristocratic members of the audience to take seats directly on the stage and to discuss the action absolutely undeterred. The produced noise and the behavioral pattern they opted for seems a violation of theatrical communication code looking back from the angle of today's theatre. However, even in the XVII century, such a behavior was considered to be discordant with actor-spectator interrelations implied within the framework of theatrical discourse. Such organization was impractical as the actors were restricted in free to movement about the stage, thus it provided a negative effect on the audience's perception of the action. As a result the issue triggered a number of rows in theatre public.

Interdependence of theatrical space and communication code is also determined by the unstable, changeable and dynamic nature of the space. It may be affected by any sound produced on the stage or coming from the audience, by any kind of movement, and in its turn it may influence both the actors' and the audience's perception of the action.

\section{Time Limits in Theatrical Communication}

Time limits of the performance are «set by the director and prescribed in the theatre programme» [4]. They also belong to the factors determining the conventional and 
regulatory nature of theatrical communication. What is of particular relevance is that the performance, already limited in time, is being completed on the stage in front of the audience. In other words, the performance comes as a result of all the participants' creative activity / enactment.

The events of the stage-play are taking place here and now, as "all that is spread out on the stage can be observed at once" [14]. It all turns the viewers into «intentional» eyewitnesses since the character of theatre communication is quasi-real and can be treated after E. Kluev [15] as an expected communicative act. A distinctive particularity of theatrical communication lies in its instantaneous topos, with its "capability to exert an immediate sensuous impact on the viewers and arouse their strong and sometimes even uncontrollable affects in them» [2]. It is it's the instantaneous character of the stage-play that makes it unique, assuming an exclusive form at the very moment. It is immediately apparent from the foregoing that there are not and cannot be two identical performances: each time an actor goes onto the stage, the played character is displaced in a different way.

Instantaneous nature of the performance determines its expressive potential. The latter is further induced with an obligatory performative feature of presence. The more intense the presence is, the more intensively affected is the audience.

The concept of presence denies the principle of actor-personage unity, claiming that it is the charismatic nature of the actor that dominates the personage and that "theatre cannot exist without actor" [14]. In blunt terms, the way a viewer sees Hamlet impersonated by a certain actor mainly depends on this actor's presence concentration on the stage, the energy and force of the latter. To conclude, the concept of presence stands for the ability of the actor "to generate the energy circulating in the space, perceived by the viewers, affecting them and even imparting them with certain features" [2].

The definition presented above deals with the concept of presence from the actor's standpoint. Anyway, it can also be applied to the audience. Only the viewers' physical presence in the hall and their cooperation with the actors may claim the success of the performance and the future of a certain theatre.

The concept of presence is directly linked with the chronotopic peculiarities of theatre communication and communication code as its moderator. Changed temporal and spatial framework and violation of the communication code by the participants in the theatrical action ruin the concept of presence and finally result in a communication failure. What has been said proves that modern technologies, electronic and multimedia technologies are likely to generate the effect of presence only, but never the presence as it is.

\section{The Order of Cooperation among Theatrical Discourse Participants}

Theatrical communication participants interrelations broadly depend on either observing or violating the communication code functioning as a pragmatic regulator.

Communication code may be viewed as a mechanism of dynamic communication and "a complex system of principles regulating the speech behavior of both counterparts in the process of communication" [15]. It implies a specific behavioral pattern of the participants' communication activity within theatrical space. The behavioral pattern is specifically defined as "a set of conventional (realized in accordance with the accepted rules) and nonconventional (arbitrary) speech acts, committed by a person or a group of people" [15]. Stated another way, theatrical discourse is effected conforming to a communication standard or a set of communication convention accepted in the society.

Therefore, if applied to theatrical discourse, the communication code enables a playwright to address the audience via the director and theatre company. The twentieth century tradition left the responsibility of sign system organizing on the director's hand [14]. Still despite the compulsoriness of the audience's response, the communication code introduces a one-way verbal communication type. The viewer assumes a silent role; the company takes responsibility for sustain of communication. Within theatrical discourse, communication is initiated in a specific way: the audience is silent and the communication is quasi-real as theatrical discourse is conventional, the contents of the play enclose nothing rhematic for the company and sometimes for the viewers as well. Regardless of that, the primary initiative of communication emanates from the viewers.

The viewers come to the theatre to take on a role of silent observers. Aware of the chosen part, the spectators are ready to follow the guidelines of the communication code. Some of the code guidelines are included in the theatre programmes and tickets, e.g. "One cannot enter the hall after the third bell has gone". A perfect example of such guidelines in the form of print or electronic theatrical texts corresponds to an immersive performance "The Black Russian" directed by M. Didenko. The company's web-site along with the playbills and theatre programmes contain a set of rules (the so-called Rules of Troekurov House), dominating the behavioral pattern and actions of the audience both during the performance and long before it starts: "The doors of the House stay open for you, but they will be closed on entry and exit at the moment indicated in your invitation. If the doors of the House are closed, you are no longer expected there. The guests are to wait outside, one shouldn't come in advance" [16].

We find it essential that the creators of the performance emphasize the obligatory nature of the certain guidelines for all and every spectator: "Before paying a visit to Troekurov House, well-known for its hospitality, we strongly recommend you to learn the following rules of the House. If our recommendation seems needless to you, we oblige you to get acquainted with the rules of the friendly Troekurov House" [16]. 
Breaking the rules can be sanctioned with removing the spectator from the hall or prohibiting an admission later.

The key feature of the theatre audience is its passive role. The communication code to some extent deprives the spectators of the possibility to move around or talk during the performance. The only thing allowed is applause or 'Bravo'-s and curtain calls when the action the audience liked is over. The sign of the spectators' ultimate respect and appreciation is to rise to their feet to applaud or to throw the flowers onto the stage.

Surprisingly, the communication code doesn't outline the ways of expressing discontent with the performance. Presumably such issues are known as violations against the code. For instance, there were hisses and whistles from the audience to the Italian ballet dancer of the XIX century Marie Taglioni, who had demonstrated traditional Russian dance to please the spectators. Another renowned case tells about a dead black cat thrown onto the stage while Elena Andreianova was dancing a part in Marius Petipa's ballet "Paquita". The humiliated dancer received support from both the company and the audience. Accompanied by a storm of applause and in total control of herself, she never terminated the performance [17].

Nevertheless, no matter how involved the audience is in the performance, there is no option for them to participate in it directly: "the theatre-goer, even quite anxious about the performance, still remains an external observer with no chance to interfere in the action even in case a character is going to kill another one" [1].

The audience's interference in the stage action is likely to affect not only the success or failure of the performance, but also to determine the repertoire and the financial strategy of a certain theatre [17]. The Old Price Riots of 1809 in London claim to be the most vivid example. The Riots were caused by rising ticket-prices at the new Theatre at Covent Garden, London, after the previous one had been destroyed by fire. The management was forced to raise the prices from six shillings to seven for the boxes, from 3 shillings and sixpence to four shillings for the pit, and the third tier, usually reserved for the public, was converted into private boxes at a rent of $£ 300$ per year. Unchanged was the price for the gallery often referred to as "pigeon holes" since people inside could only see the legs of the performers. The gallery, calling themselves $O$. P. (old prices), were responsible for actually breaking out the riots. At the very beginning of the performance when the curtain was only going up the audience went so noisy that despite all the actors' efforts there was no chance for them to be heard even in the front stalls. The riot continued throughout the play and later they were to last another 64 days to end up with John Philip Kemble, the manager of the theatre, being forced to make a public apology.

Nevertheless, a modern spectator is lucky enough to escape the usual sitting routine and to move throughout the performance. It is immersive theatre that offers such an opportunity and implies an effect of the audience plunged into the plot and show and giving at the same time some freedom of action. "The Black Russian" show which has already been mentioned cannot be signified as a typical theatrical straight performance. It rather turns into a social event, as the audience never restricted only to applause. The spectators acquire a feeling of involvement and unimpeded participation in the action together with the actors. Still, the audience's behavior can to some extent be compared to "a butterfly actuating something which can cause or prevent a hurricane with a flap of the wing" [2].

Theatrical space being quite unstable, all the participants are under noticeable emotional impact, which can provoke the actually motionless and speechless audience to take some action. In this case the only way to handle the situation and to deter the chaos is to opt for the communication code determining both the communication space and the actions of the participants constituting it. A manifestation of the communication code functioning as a regulator is the law of the XIX century adopted to control the audience's behavior in the theatre. Before the law came into force spectators were free to interfere in the course of the performance, to dispute with actors, to cry out some approving or discouraging remarks, to eat and drink without leaving the hall.

Such restrictions to the behavior of the audience are reasonable, as "the sounds produced in the public become the noise breaching the action, an obstacle to overcome" [6]. Any random or intentional sound makes an integral part of the performance, affects the overall performative space and every of its constituents. Similar effect is produced by mobile phone calls, though the audience is kindly asked to switch them off before the performance starts. As a matter of interest, such announcements vary from theatre to theatre in correlation with their style. Exemplarily in the preperformance announcement heard by the visitors of the Taganka theatre in Moscow, its founder and the ideological inspirer Yury Lyubimov warns the spectators of the necessity to switch off all communication means. The announcement speaks of respect towards each of the spectators. What makes the announcement special is a witty remark in the end: "We kindly beg, don't you smudge your gum on under the seats!". The appeal is far from being trivial and it prompts smiles and even laughter in the audience. An in-depth approach to the phrase containing examples of spoken language used in a lofty context hints at some implicit connotations. On the one hand, informality contribute to establishing a tighter link with spectators from all walks of life which surely adds to promoting theatre in common audience. Still, such a pompous presentation emphasizes the elitist pattern of theatre as a social institution and of the company as acolytes of the sublime.

In its turn, a similar announcement heard in the Gogol-center theatre differs in style, linguistic image and the connotation implied. The audience is addressed twice: before the start of the action and after the interval by one of the assistants. Customarily, it's done by a student, who gathers expertise while assisting the company during rehearsals and performances, using a microphone. The focus is on the prohibition to use cameras, as the company is mainly formed by actors 
popular among the youth eager to take a picture of their favorite actor. Flashes of the cameras disturb the performing actors; taken photos violate the intellectual property law.

\section{Conclusion}

In conclusion we would emphasize that productivity of theatrical communication, as of any other kind of speech activity, correlates outright with proper perception and following interpretation of information within the parameters of the on-going communication. Correct interpretation manifests itself in effective verbal communication determined and regulated by communication code. If Grice's cooperative principle and Leech's maxim of politeness are in the core of the general verbal communication code, then it proves relevant to distinguish the following principles applied to theatrical discourse:

- the principle of temporal and spatial organization;

- $\quad$ the principle of muteness;

- $\quad$ the principle of prescript observation;

- the axiological awareness principle.

The first three principles are determined by the pragmatics of theatrical communication space as well as by the specific interrelationships of the participants. In its turn, the axiological awareness principle implies theatre functioning as a culture institution. The modern world is facing a new era of post-humanism, characterized by values, including the ever-absolute truth and goodness, getting unstable under some historical conditions or crises [18]. We can't but mention that all human values both basic moral and purposive constructive like science, progress and humanism are affected. Thereat the ritualized, institutional and conventional semiotic unit of theatre, regulated by the principles of communication code, functions as an analyzer, preserver of moral values, moderator of social stability values, indicator of people's value awareness and producer of new cognitive and ethical values.

\section{References}

1. K. Elam, The Semoitics of theatre and drama (Taylor \& Francis Group, 2005)

2. E.-F. Lihte, The transformative power of performance (Suhrkamp Verlag, 2015)

3. B. Gasparov, Language. Memory. Image. Language existence linguistics (Новое литературное собрание, 1996)

4. L.A. Borbotko, Scient. N. Mod. Ling. and method.and-did. research 3 (2014)

5. S. Ognenovski, Intercult. Com. (1999)

6. V. Babayan, The Act in a two-person talk with a silent bystander (RIC MUBiT, 2008)

7. S. Plotnikova, Discourse and discursive space (LENAND, 2018)
8. O. Sulejmanova, Vestn. MGPU 3(19) (2015)

9. M. Drobiysheva, Dalmatian-Dubrovnik Renaissance: Marin Držić' works (Saint Petersburg Univers. Publishing house, 2014)

10. A. Smirnov, On hist. of Europ. Theatre (1922)

11. S. Denisenko, Pushkin's texts on the theatre stage in XIX century (Nestor-Istoriya 2010)

12. M. Yampol'sky'j Observer. On history on visual perception (Masterskaya SEANS, 2012)

13. M. Puchner, Theatre Research Int., 29, 1 (2004).

14. N. Sahid, Humaniora 25 (2013)

15. R. Klyuev, Verbal communication (RIPOL KLASSIK, 2002)

16. The Black Russian Show, URL: https://blackrussianshow.ru/about

17. E. Khaichenko, Respectable audience or a spectator becoming an actor (GITIS, 2016)

18. L.Vikoulova, E. Sérébrénnikova, Cahiers francorusses de linguistique et de didactique. Ensegnement et apprentissage $d u$ français et $d u$ russe langues étrangères : parcours linguistiques et didactiques: Recueil d'article 1 (2014) 